\title{
Mathematics - How do students and teachers perceive it?
}

\author{
Nurgül Düzenli Gökalp ${ }^{\mathrm{a}}$ \\ Corresponding author: duzenlinurgul@gmail.com \\ aMathematics Education Department, Dumlupinar University, Kutahya, Turkey
}

Keywords: Perceptions of mathematics, perception, definition of mathematics

\begin{abstract}
The current study explored mathematics perceptions of teachers and high school students. The online survey consisting of three open-ended questions was answered by 104 high school students and 92 mathematics teachers. A qualitative descriptive research approach was applied to analyse the data. The results of this study showed that mathematics is seen as a branch of science, everything, explanations of concepts with numbers, language, universal language, language of nature, language of universe, life, method, numbers, and tool. Moreover, it was found that there are differences in perceptions between students and teachers as well as males and females. The results of this study extend what we know about student and teacher perceptions of mathematics and add an important contribution to mathematics education research.
\end{abstract}

\section{Introduction}

We use mathematics in almost everything in our daily lives, from counting the money that we use to buy the essentials from the grocery to simply counting the cost of something we have purchased. We can assume that mathematics is simply inevitable in our lives. Despite this, it is apparent that students have a tendency to dislike mathematics as a course. This may be because students view mathematics as something that deals only with numbers and calculations (Borthwick, 2011; Epstein, Mendick, \& Moreau, 2010; Young- Loveridge, Taylor, Sharma, \& Hawera, 2006). Mathematics in schools is seen as a language (Otte, de Barros, 2015).

The term of mathematics comes from the Greek word $\mu \alpha \dot{\theta} \theta \eta \alpha$ (máthēma). Máthēma simply means "what one learns" or "what one gets to know". Furthermore, this term later changed into $\mu \alpha \theta \eta \mu \alpha \tau \iota \kappa o ́ s$ (mathēmatikós) which means "studious" or "related to learning" (Ribeiro, 2013). On the other hand, one of the Greek philosophers, Aristotle, defined mathematics as the science of quantity. This definition had been widely accepted until the 18th century (Franklin, 2009). The Merriam-Webster dictionary defines mathematics as "the science of numbers and their operations, interrelations, combinations, generalizations, and abstractions and of space configurations and their structure, measurement, transformations, and generalizations" (Merriam-Webster, 2019), which also defines mathematics in a similar way to Aristotle. These definitions were questioned when the content knowledge of mathematics started to be more broad and new definitions were proposed. Some of these definitions have been related to deductive scope while others have been related to abstract context of the field (Cajori, 1893). However, the definition of mathematics is still debated. Today, even for our modern mathematicians and professionals, there is no agreed meaning of mathematics. Different professors have their own view of the discipline and come up with different definitions for it (Mura, 1993). 
Several studies have been conducted to investigate mathematics perceptions. Burton (2012) explored perceptions of elementary pre-service teachers. The participants of the study were asked to draw mathematics as an illustration of how they perceive it. It was observed that negative expressions in the drawings were mostly related to the classroom. On the other hand, the drawings illustrating real-life connections of mathematics showed positive attitudes. Another study was carried out by Foley (2016) with fourteen girls from the ages eight to nine. The results of that study showed that the girls perceived mathematics either as subject or a part of their life. Moreover, it was concluded that numbers and calculations were a prominent factor affecting their views on seeing something related with mathematics.

In this study, the researcher explored the students and teachers' perceptions of mathematics with three open-ended questions: (1) What is mathematics?, (2) Why do we learn mathematics?, and (3) What are some examples of mathematics in daily life?.

\section{Research questions}

There are three research questions in this study. The following questions were investigated:

- How do high school students perceive mathematics?

- How do mathematics teachers perceive mathematics?

- What are the differences between female and male students and teachers in their perceptions of mathematics?

\section{Method}

\section{Design of the study}

In this study, the qualitative descriptive research method (also known as qualitative description) was employed. This fairly new research method is commonly used in nursing research (Sandelowski 2000; Parse 2001). However, it has been successfully used in other fields also (Gokalp, 2018; Mendez-Shannon, 2010).

\section{Data collection and analysis}

The data was collected with the help of an online survey that was published concurrently on several popular education themed websites for four months in 2017. Participant consent was obtained and responses were collected without obtaining names and other sensitive information. As the current study only focused on high school students and mathematics teachers, the data collected during this period was filtered to consist of only the teachers and the students.

The survey had three structured questions:

(1) What is mathematics?

(2) Why do we learn mathematics?

(3) What are some examples of mathematics in daily life?

The participants were asked the above questions and their responses were recorded into the database along with the timestamp and the user IP addresses to check if there were any duplicated records. After cleaning the data, the researcher identified themes emerging from the responses for each question. In order to increase the reliability, another expert was asked to check the response clusters and emerging themes. The data file with an extra column for agreement was sent to the expert, who was asked to indicate his agreement for each entry. It was seen that there was $91.8 \%$ agreement between the expert and the researcher. Only 16 cases out of 196 were not agreed. The researcher rechecked those entries and changed four of them. Microsoft Excel was used to filter and clean the data for analysis. 


\section{Participants}

In the current study, the data from 104 high school students (53.1\% of all participants) and 92 primary and secondary school mathematics teachers (46.9\% of all participants) were analysed. Table 1 shows the number of the survey participants with respect to gender and occupation.

Table 1. Occupation of online survey participants

\begin{tabular}{llrrr}
\hline & & \multicolumn{2}{c}{ job } & \\
\cline { 3 - 4 } \multicolumn{1}{c}{ gender } & & student & teacher & \multicolumn{2}{c}{ Total } \\
\hline \multirow{2}{*}{ male } & Count & 60.00 & 64.00 & 124.00 \\
& \% of Total & $30.6 \%$ & $32.7 \%$ & $63.3 \%$ \\
\multirow{2}{*}{ female } & Count & 44.00 & 28.00 & 72.00 \\
& \% of Total & $22.4 \%$ & $14.3 \%$ & $36.7 \%$ \\
\multirow{2}{*}{ Total } & Count & 104.00 & 92.00 & 196.00 \\
& \% of Total & $53.1 \%$ & $46.9 \%$ & $100.0 \%$ \\
\hline
\end{tabular}

As it can be seen from Table 1, 63.3\% ( $\mathrm{f}=124)$ of the participants were male and $36.7 \%(\mathrm{f}=72)$ of the participants were female. Almost half of the male participants $(f=64)$ were teacher; however most of the female participants were students $(\mathrm{f}=44)$. The number of the female teachers was 28 . The mean of the students' age was 17.13 whereas the mean of the teachers' age was 38.04. The overall mean age for all participants was 26.95 .

\section{Results}

\section{What is mathematics?}

The answers to the survey questions are grouped into 11 themes as follows: branch of science, everything, explanations of concepts with numbers, language, universal language, language of nature, language of universe, life, method, numbers, and tool (see Table 2).

When we look at all data without filtering based on gender or occupation, we see that the most popular theme is 'language of universe' $(16.8 \%, \mathrm{f}=33)$. Moreover, we can combine the themes of 'universal language', 'language of nature', and 'language of universe' with theme of 'language'. Because all these themes are about how mathematics is defined as a language. In this case it can be said that 69 of all participants see mathematics as a language. Some of them just define mathematics as a language without attributing anything about where we use this language $(\mathrm{f}=8)$. However, most of the participants who define mathematics as language go further. For example, one of the participant's answers was:

For me, mathematics is the language that all people can communicate each other globally without the need of any other language. People can use mathematics at anywhere of the world, and anyone can understand what they say.

This was one of the answers that define mathematics as a 'universal language'.

Moreover, several participants $(\mathrm{f}=20)$ defined mathematics as 'language of nature'. Their answers were mostly 'Mathematics is the language of the nature', which makes it very easy to classify these answers under this theme. 
Table 2. What is mathematics? - gender comparison

\begin{tabular}{|c|c|c|c|c|}
\hline \multirow[b]{2}{*}{ mathematics } & & \multicolumn{2}{|c|}{ gender } & \multirow[b]{2}{*}{ Total } \\
\hline & & male & female & \\
\hline \multirow{2}{*}{ branch of science } & Count & 16.00 & 8.00 & 24.00 \\
\hline & $\%$ within column & $12.9 \%$ & $11.1 \%$ & $12.2 \%$ \\
\hline \multirow{2}{*}{ everything } & Count & 4.00 & 8.00 & 12.00 \\
\hline & $\%$ within column & $3.2 \%$ & $11.1 \%$ & $6.1 \%$ \\
\hline \multirow{2}{*}{ explanations of concepts with numbers } & Count & 8.00 & 13.00 & 21.00 \\
\hline & $\%$ within column & $6.5 \%$ & $18.1 \%$ & $10.7 \%$ \\
\hline \multirow{2}{*}{ language } & Count & 8.00 & 0.00 & 8.00 \\
\hline & $\%$ within column & $6.5 \%$ & $0.0 \%$ & $4.1 \%$ \\
\hline \multirow{2}{*}{ language - universal } & Count & 4.00 & 4.00 & 8.00 \\
\hline & $\%$ within column & $3.2 \%$ & $5.6 \%$ & $4.1 \%$ \\
\hline \multirow{2}{*}{ language of nature } & Count & 20.00 & 0.00 & 20.00 \\
\hline & $\%$ within column & $16.1 \%$ & $0.0 \%$ & $10.2 \%$ \\
\hline \multirow{2}{*}{ language of universe } & Count & 17.00 & 16.00 & 33.00 \\
\hline & $\%$ within column & $13.7 \%$ & $22.2 \%$ & $16.8 \%$ \\
\hline \multirow{2}{*}{ life } & Count & 18.00 & 4.00 & 22.00 \\
\hline & $\%$ within column & $14.5 \%$ & $5.6 \%$ & $11.2 \%$ \\
\hline \multirow{2}{*}{ method } & Count & 5.00 & 0.00 & 5.00 \\
\hline & $\%$ within column & $4.0 \%$ & $0.0 \%$ & $2.6 \%$ \\
\hline \multirow{2}{*}{ numbers } & Count & 4.00 & 10.00 & 14.00 \\
\hline & $\%$ within column & $3.2 \%$ & $13.9 \%$ & $7.1 \%$ \\
\hline \multirow{2}{*}{ tool } & Count & 11.00 & 0.00 & 11.00 \\
\hline & $\%$ within column & $8.9 \%$ & $0.0 \%$ & $5.6 \%$ \\
\hline \multirow{2}{*}{ other } & Count & 9.00 & 9.00 & 18.00 \\
\hline & $\%$ within column & $7.3 \%$ & $12.5 \%$ & $9.2 \%$ \\
\hline \multirow{2}{*}{ Total } & Count & 124.00 & 72.00 & 196.00 \\
\hline & $\%$ within column & $100.0 \%$ & $100.0 \%$ & $100.0 \%$ \\
\hline
\end{tabular}

The ones ( $\mathrm{f}=33$ ) who define mathematics as 'language of the universe' gave more details on their definitions. For example:

Mathematics is the sequence of the codes that allows us to understand the universe. It is the language of universe.

Mathematics is the language that is used to describe the realities in the universe.

Mathematics is simply the digital language of the universe.

Another prominent theme was the 'branch of science' evident in the answers of 24 participants $(12.2 \%)$. For example:

Mathematics is a branch of science that allows us to convert laws of nature into something that can be understood by all.

Mathematics is the science of the numbers. 


\begin{abstract}
Mathematics is the one of the oldest branch of science. It consists of many concepts such as numbers, functions, algorithms, and clusters.
\end{abstract}

The next emerging theme was 'life' from the answers from 22 of all participants (11.2\%). Most of these participants simply defined mathematics as life itself. One of the examples of these answers is as follow:

\title{
Mathematics is life. We cannot think about anything that is not having any mathematics in it. It is at everywhere around us.
}

Another theme that emerged from the data was 'explanation of concepts with numbers' as 21 of all participants $(10.7 \%)$ defined mathematics in this way. One of the examples of these answers is as follow:

\section{It is the series of equations and operations that used to explain concepts with the help of numbers in a digital way.}

Another theme that emerged from the data was 'numbers' as 14 of all participants $(7.1 \%)$ defined mathematics in this way. These participants defined mathematics as follow: 'It is just very complicated numbers', 'mathematics is formulas and numbers', and 'mathematics is numbers'.

In addition to the above themes, 12 of all participants $(6.1 \%)$ defined mathematics as 'everything', 11 of all participants (5.6\%) defined mathematics as 'tool', and 5 of all participants $(2.6 \%)$ defined mathematics as 'method'. Furthermore, it was not possible to put 18 of the participants' answers in any of the themes, so they are presented as 'other' in Table 2 .

In Table 2, the results with respect to gender are also presented. It was seen that while the top theme for males was 'language of nature' (according to $16.1 \%$ of male participants), it was 'language of universe' for females (according to $22.2 \%$ of female participants). It is interesting that only males defined mathematics as 'language of nature', and none of the females defined mathematics in that way. Other male-only themes were the 'tool', 'method', and 'language'.

These themes were also compared with respect to occupation of the participants- teachers and students (see Table 3). The top three emerged themes for students were 'branch of science' $(19.2 \%, \mathrm{f}=20)$, 'life' $(17.3 \%, \mathrm{f}=18)$, and 'language of universe' $(12.5 \%, \mathrm{f}=13)$. On the other hand, the top three for the teachers were 'language of universe' $(21.7 \%, \mathrm{f}=20)$, 'language of nature' $(17.4 \%, \mathrm{f}=16)$, and 'explanation of concepts with numbers' $(9.8 \%, \mathrm{f}=9)$. 
Table 3. What is mathematics? - occupation comparison

\begin{tabular}{|c|c|c|c|c|}
\hline \multirow[b]{2}{*}{ mathematics } & & \multicolumn{2}{|c|}{ job } & \multirow[b]{2}{*}{ Total } \\
\hline & & student & teacher & \\
\hline \multirow{2}{*}{ branch of science } & Count & 20.00 & 4.00 & 24.00 \\
\hline & $\%$ within column & $19.2 \%$ & $4.3 \%$ & $12.2 \%$ \\
\hline \multirow{2}{*}{ everything } & Count & 4.00 & 8.00 & 12.00 \\
\hline & $\%$ within column & $3.8 \%$ & $8.7 \%$ & $6.1 \%$ \\
\hline \multirow{2}{*}{ explanations of concepts with numbers } & Count & 12.00 & 9.00 & 21.00 \\
\hline & $\%$ within column & $11.5 \%$ & $9.8 \%$ & $10.7 \%$ \\
\hline \multirow{2}{*}{ language } & Count & 0.00 & 8.00 & 8.00 \\
\hline & $\%$ within column & $0.0 \%$ & $8.7 \%$ & $4.1 \%$ \\
\hline \multirow{2}{*}{ language - universal } & Count & 4.00 & 4.00 & 8.00 \\
\hline & $\%$ within column & $3.8 \%$ & $4.3 \%$ & $4.1 \%$ \\
\hline \multirow{2}{*}{ language of nature } & Count & 4.00 & 16.00 & 20.00 \\
\hline & $\%$ within column & $3.8 \%$ & $17.4 \%$ & $10.2 \%$ \\
\hline \multirow{2}{*}{ language of universe } & Count & 13.00 & 20.00 & 33.00 \\
\hline & $\%$ within column & $12.5 \%$ & $21.7 \%$ & $16.8 \%$ \\
\hline \multirow{2}{*}{ life } & Count & 18.00 & 4.00 & 22.00 \\
\hline & $\%$ within column & $17.3 \%$ & $4.3 \%$ & $11.2 \%$ \\
\hline \multirow{2}{*}{ method } & Count & 4.00 & 1.00 & 5.00 \\
\hline & $\%$ within column & $3.8 \%$ & $1.1 \%$ & $2.6 \%$ \\
\hline \multirow{2}{*}{ numbers } & Count & 10.00 & 4.00 & 14.00 \\
\hline & $\%$ within column & $9.6 \%$ & $4.3 \%$ & $7.1 \%$ \\
\hline \multirow{2}{*}{ tool } & Count & 3.00 & 8.00 & 11.00 \\
\hline & $\%$ within column & $2.9 \%$ & $8.7 \%$ & $5.6 \%$ \\
\hline \multirow{2}{*}{ other } & Count & 12.00 & 6.00 & 18.00 \\
\hline & $\%$ within column & $11.5 \%$ & $6.5 \%$ & $9.2 \%$ \\
\hline \multirow{2}{*}{ Total } & Count & 104.00 & 92.00 & 196.00 \\
\hline & $\%$ within column & $100.0 \%$ & $100.0 \%$ & $100.0 \%$ \\
\hline
\end{tabular}

\section{Why do we learn mathematics?}

The second question aimed to explore what motivates people to learn mathematics. Analysis of the data yielded 6 themes as follows: 'personal development', 'to have a comfortable life', 'to understand life', 'to understand nature', 'to understand the universe', and 'we need' (see Table 4).

The top theme that emerged from the data was 'we need' $(30.1 \%, \mathrm{f}=59)$. It was seen that most of the participants stated that they learn mathematics because they simply need it. Here the several examples of the answers.

Without mathematics, we cannot do many things; they become impossible.

Mathematics is needed. Everyone should have some mathematics

knowledge.

Because, we need mathematics in our daily life.

Because, at everywhere of our life we need mathematics. For example, at grocery we need it, at our jobs we need it, when we travel to somewhere we need it, so on. 
The second theme was 'personal development' $(15.8 \%, \mathrm{f}=31)$. The participants stated that they learn mathematics because of their personal development. For example:

For my point of view, I want to learn and know more about everything. I see this is only possible with mathematics.

We learn mathematics because we want to improve critical thinking skills, to be open-minded, and to have higher order thinking skills such as analyzing.

I have to learn because I should improve myself. It is the only way to pass the exams.

Table 4. Why do we learn mathematics? - gender comparison

\begin{tabular}{|c|c|c|c|c|}
\hline \multirow[b]{2}{*}{ whymathematic } & & \multicolumn{2}{|c|}{ gender } & \multirow[b]{2}{*}{ Total } \\
\hline & & male & female & \\
\hline \multirow{2}{*}{ personal development } & Count & 20.00 & 11.00 & 31.00 \\
\hline & $\%$ within column & $16.1 \%$ & $15.3 \%$ & $15.8 \%$ \\
\hline \multirow{2}{*}{ to have a comfortable life } & Count & 5.00 & 8.00 & 13.00 \\
\hline & $\%$ within column & $4.0 \%$ & $11.1 \%$ & $6.6 \%$ \\
\hline \multirow{2}{*}{ to understand life } & Count & 9.00 & 15.00 & 24.00 \\
\hline & $\%$ within column & $7.3 \%$ & $20.8 \%$ & $12.2 \%$ \\
\hline \multirow{2}{*}{ to understand nature } & Count & 32.00 & 4.00 & 28.00 \\
\hline & $\%$ within column & $25.8 \%$ & $5.6 \%$ & $14.3 \%$ \\
\hline \multirow{2}{*}{ to understand the universe } & Count & 12.00 & 12.00 & 24.00 \\
\hline & $\%$ within column & $9.7 \%$ & $16.7 \%$ & $12.2 \%$ \\
\hline \multirow{2}{*}{ we need } & Count & 43.00 & 16.00 & 59.00 \\
\hline & $\%$ within column & $34.7 \%$ & $22.2 \%$ & $30.1 \%$ \\
\hline \multirow{2}{*}{ other } & Count & 3.00 & 6.00 & 9.00 \\
\hline & $\%$ within column & $2.4 \%$ & $8.3 \%$ & $4.6 \%$ \\
\hline \multirow{2}{*}{ Total } & Count & 124.00 & 72.00 & 196.00 \\
\hline & $\%$ within column & $100.0 \%$ & $100.0 \%$ & $100.0 \%$ \\
\hline
\end{tabular}

The third theme that emerged from the data was 'to understand nature'. Twenty-eight of the participants $(14.3 \%)$ stated that they learn mathematics in order to understand nature better. Some of these answers are as follows:

Mathematics explains the nature. Every event in nature has a mathematical explanation. We should learn mathematics. Otherwise, we cannot define and prove anything.

In order to interpret natural events better and to have more realistic results, we need mathematical knowledge.

Mathematics is must to understand, interpret, and define the nature.

Another theme that emerged from the data was 'to understand life'. It was seen that 24 of the participants $(12.2 \%)$ stated that they learn mathematics in order to understand life. For example, one participant answered the question, as 'in order to have meaningful life, we have to learn mathematics.' 
One other theme that emerged from the data was 'to understand the universe'. It was seen that 24 of the participants (12.2\%) stated that they learn mathematics in order to understand life. Lastly, 13 of the participants $(6.6 \%)$ stated that they learn mathematics 'to have a comfortable life'.

Table 4 also provides a comparison of males and females. It can be seen from the table that the top theme, 'we need', is the same for both genders. However, while $34.7 \%$ of the males state that they learn mathematics because they need it, only $22.2 \%$ of the females state the same. The top second and third themes are different for each gender. For males, the second emerging theme is 'to understand nature' $(25.8 \%, \mathrm{f}=32)$. It should be noted that, this theme is the least present theme for the females $(5.6 \%, \mathrm{f}=4)$. The third theme for males is 'personal development' $(16.1 \%, \mathrm{f}=20)$. On the other hand, for females, the second emerging theme is 'to understand life' $(20.8 \%, \mathrm{f}=15)$, and the third theme is 'to understand the universe' $(16.7 \%, \mathrm{f}=12)$.

Comparisons were also made with respect to participants' occupation (see Table 5). The order of the themes for students is (1) 'we need', (2) 'personal development', (3) 'to have a comfortable life', (4) 'to understand the universe', (5) 'to understand life', and (6) 'to understand nature'. On the other hand, the order for teachers is (1) 'to understand nature', (2) 'we need', (3) 'to understand life', (4) 'to understand the universe', (5) 'personal development', and (6) 'to have a comfortable life'.

Table 5. Why do we learn mathematics? - occupation comparison

\begin{tabular}{llrrr}
\hline \multirow{2}{*}{ whymathematics } & & \multicolumn{2}{c}{ job } & \multicolumn{1}{c}{ Total } \\
\cline { 3 - 4 } personal development & Count & student & teacher & 31.00 \\
& \% within column & 19.00 & 12.00 & $15.8 \%$ \\
to have a comfortable life & Count & $18.3 \%$ & $13.0 \%$ & 13.00 \\
& $\%$ within column & 13.00 & 0.00 & $6.6 \%$ \\
to understand life & Count & $12.5 \%$ & $0.0 \%$ & 24.00 \\
& $\%$ within column & 9.00 & 15.00 & $12.2 \%$ \\
to understand nature & Count & $8.7 \%$ & $16.3 \%$ & 28.00 \\
& $\%$ within column & 8.00 & 28.00 & $14.3 \%$ \\
to understand the universe & Count & $7.7 \%$ & $30.4 \%$ & 24.00 \\
& $\%$ within column & 12.00 & 12.00 & $12.2 \%$ \\
we need & Count & $11.5 \%$ & $13.0 \%$ & 59.00 \\
& $\%$ within column & 41.00 & 18.00 & $30.1 \%$ \\
other & Count & $39.4 \%$ & $19.6 \%$ & 9.00 \\
& $\%$ within column & 2.00 & 7.00 & $4.6 \%$ \\
Total & Count & $1.9 \%$ & $7.6 \%$ & 196.00 \\
& $\%$ within column & 104.00 & 92.00 & $100.0 \%$ \\
\hline
\end{tabular}

The researcher further analysed the data by comparing the answers of the first two questions (see Table 6). Most of the participants who defined mathematics as branch of science (16 out of 24) stated that they learn mathematics because they simply need it. 
Table 6. Why do we learn mathematics? vs What is mathematics?

\begin{tabular}{|c|c|c|c|c|c|c|c|c|}
\hline \multirow[b]{2}{*}{ mathematics } & \multicolumn{7}{|c|}{ whymathematics } & \multirow[b]{2}{*}{ Total } \\
\hline & $\begin{array}{c}\text { personal } \\
\text { development }\end{array}$ & $\begin{array}{c}\text { comfortabl } \\
\text { life }\end{array}$ & $\begin{array}{c}\text { understand } \\
\text { life } \\
\end{array}$ & $\begin{array}{c}\text { understand } \\
\text { nature } \\
\end{array}$ & $\begin{array}{c}\text { understand } \\
\text { universe }\end{array}$ & $\begin{array}{c}\text { we } \\
\text { need }\end{array}$ & other & \\
\hline branch of science & 4 & 0 & 4 & 0 & 0 & 16 & 0 & 24 \\
\hline everything & 8 & 0 & 0 & 4 & 0 & 0 & 0 & 12 \\
\hline $\begin{array}{l}\text { explanations of } \\
\text { concepts with numbers }\end{array}$ & 4 & 1 & 2 & 4 & 0 & 5 & 5 & 21 \\
\hline language & 4 & 0 & 0 & 4 & 0 & 0 & 0 & 8 \\
\hline language - universal & 3 & 0 & 0 & 4 & 0 & 0 & 1 & 8 \\
\hline language of nature & 0 & 0 & 0 & 12 & 0 & 6 & 2 & 20 \\
\hline language of universe & 0 & 0 & 3 & 4 & 12 & 13 & 1 & 33 \\
\hline life & 4 & 0 & 8 & 2 & 4 & 4 & 0 & 22 \\
\hline method & 1 & 0 & 0 & 0 & 0 & 4 & 0 & 5 \\
\hline numbers & 0 & 6 & 4 & 0 & 0 & 4 & 0 & 14 \\
\hline other & 3 & 6 & 3 & 2 & 4 & 0 & 0 & 18 \\
\hline tool & 0 & 0 & 0 & 0 & 4 & 7 & 0 & 11 \\
\hline Total & 31 & 13 & 24 & 36 & 24 & 59 & 9 & 196 \\
\hline
\end{tabular}

What is the place of mathematics in our daily life?

For the last question of the survey, the participants were asked to give some examples related to mathematics from their daily life. Similar to the first two questions, the researcher identified the emerging themes from the answers and an expert re-checked the themes in order to ensure reliability and credibility. In Table 7 , these themes, along with the participants' gender, are presented.

The researcher identified 7 themes: 'concepts', 'daily life calculations', 'daily life facts', 'everything', 'jobs', 'shopping', and 'technology related'.

Table 7. What is the place of mathematics in our daily life? - gender comparison

\begin{tabular}{|c|c|c|c|c|}
\hline \multirow{2}{*}{\multicolumn{2}{|c|}{ dailymathematics }} & \multicolumn{2}{|c|}{ gender } & \multirow[b]{2}{*}{ Total } \\
\hline & & Male & Female & \\
\hline \multirow{2}{*}{ concepts } & Count & 4.00 & 4.00 & 8.00 \\
\hline & $\%$ within column & $3.2 \%$ & $5.9 \%$ & $4.2 \%$ \\
\hline \multirow{2}{*}{ daily life calculations } & Count & 59.00 & 31.00 & 90.00 \\
\hline & $\%$ within column & $47.6 \%$ & $45.6 \%$ & $46.9 \%$ \\
\hline \multirow{2}{*}{ daily life facts } & Count & 12.00 & 16.00 & 28.00 \\
\hline & $\%$ within column & $9.7 \%$ & $23.5 \%$ & $14.6 \%$ \\
\hline \multirow{2}{*}{ everything } & Count & 12.00 & 8.00 & 20.00 \\
\hline & $\%$ within column & $9.7 \%$ & $11.8 \%$ & $10.4 \%$ \\
\hline \multirow{2}{*}{ jobs } & Count & 25.00 & 0.00 & 25.00 \\
\hline & $\%$ within column & $20.2 \%$ & $0.0 \%$ & $13.0 \%$ \\
\hline \multirow{2}{*}{ shopping } & Count & 0.00 & 9.00 & 9.00 \\
\hline & $\%$ within column & $0.0 \%$ & $13.2 \%$ & $4.7 \%$ \\
\hline \multirow{2}{*}{ technology related } & Count & 12.00 & 0.00 & 12.00 \\
\hline & $\%$ within column & $9.7 \%$ & $0.0 \%$ & $6.3 \%$ \\
\hline \multirow{2}{*}{ Total } & Count & 124.00 & 68.00 & 192.00 \\
\hline & $\%$ within column & $100.0 \%$ & $100.0 \%$ & $100.0 \%$ \\
\hline
\end{tabular}


Almost half of the participants $(49.6 \%, \mathrm{f}=90)$ gave examples of several daily life calculations for mathematics in their life: making calculations when shopping, knowing how long it would take to travel to somewhere, efficient use of time and several resources, probability of game results and so on.

$14.6 \%$ of the participants $(\mathrm{f}=28$ ) provided daily life facts as the examples of mathematics in their life. For example: the ratio of the snail shell, earth orbiting around the sun, orbital inclination of earth, maximum air filled in lungs during breathing, number of breaths during the day and so on.

Job related examples were given by $13.0 \%$ of the participants $(\mathrm{f}=25)$. For example, one of the participants stated that 'Without mathematics, it is not possible to construct the buildings. Architects need mathematics. All jobs have somehow mathematics in them'. Engineering, construction, salesmen and trading, scientists, and manufacturing were other job-related examples given by the participants.

$10.4 \%$ of the participants $(\mathrm{f}=20)$ stated that everything around us related with mathematics. Technology related examples such as computers and mobile phones were given by $6.3 \%$ of the participants $(\mathrm{f}=12)$. Moreover, $4.7 \%$ of the participants $(\mathrm{f}=9)$ simply gave shopping as the example of mathematics in their life. Though this theme could be combined with the daily life calculations, the researcher decided to report it separately as they did not go further by talking about calculations or discounts. Finally, the last theme for this question was concepts, which only includes mathematical concepts such as probability, numbers, functions and so on. Only $4.2 \%$ of the participants $(\mathrm{f}=8)$ gave such examples.

Table 7 also provides a gender comparison. As is shown, jobs and technology related daily life examples were only given by males. Moreover, shopping related examples were only given by females. Furthermore, while only $9.7 \%$ of the males gave daily life facts as examples of mathematics, $23.5 \%$ of the females did the same.

Students and teachers were also compared with their examples of daily life mathematics (see Table 8). Shopping and concept related examples were only given by students. There were huge differences between teachers and students at the daily life facts, everything, and jobs in the favor of teachers.

The researcher also explored the daily life examples distribution over the self-defined mathematics (see Table 9). The ones who defined mathematics as a branch of science only gave daily life calculations, shopping, and technology related examples of mathematics in daily life. All of the participants who defined mathematics as method gave the daily life calculations as the examples. 
Table 8. What is the place of mathematics in our daily life? - occupation comparison

\begin{tabular}{|c|c|c|c|c|}
\hline \multirow[b]{2}{*}{ dailymathematics } & & \multicolumn{2}{|c|}{ job } & \multirow[b]{2}{*}{ Total } \\
\hline & & student & teacher & \\
\hline \multirow{2}{*}{ concepts } & Count & 8.00 & 0.00 & 8.00 \\
\hline & $\%$ within column & $8.0 \%$ & $0.0 \%$ & $4.2 \%$ \\
\hline \multirow{2}{*}{ daily life calculations } & Count & 50.00 & 40.00 & 90.00 \\
\hline & $\%$ within column & $50.0 \%$ & $43.5 \%$ & $46.9 \%$ \\
\hline \multirow{2}{*}{ daily life facts } & Count & 12.00 & 16.00 & 28.00 \\
\hline & $\%$ within column & $12.0 \%$ & $17.4 \%$ & $14.6 \%$ \\
\hline \multirow{2}{*}{ everything } & Count & 4.00 & 16.00 & 20.00 \\
\hline & $\%$ within column & $4.0 \%$ & $17.4 \%$ & $10.4 \%$ \\
\hline \multirow{2}{*}{ jobs } & Count & 9.00 & 16.00 & 25.00 \\
\hline & $\%$ within column & $9.0 \%$ & $17.4 \%$ & $13.0 \%$ \\
\hline \multirow{2}{*}{ shopping } & Count & 9.00 & 0.00 & 9.00 \\
\hline & $\%$ within column & $9.0 \%$ & $0.0 \%$ & $4.7 \%$ \\
\hline \multirow{2}{*}{ technology related } & Count & 8.00 & 4.00 & 12.00 \\
\hline & $\%$ within column & $8.0 \%$ & $4.3 \%$ & $6.3 \%$ \\
\hline \multirow{2}{*}{ Total } & Count & 100.00 & 92.00 & 192.00 \\
\hline & $\%$ within column & $100.0 \%$ & $100.0 \%$ & $100.0 \%$ \\
\hline
\end{tabular}

Table 9. What is the place of mathematics in our daily life? vs What is mathematics?

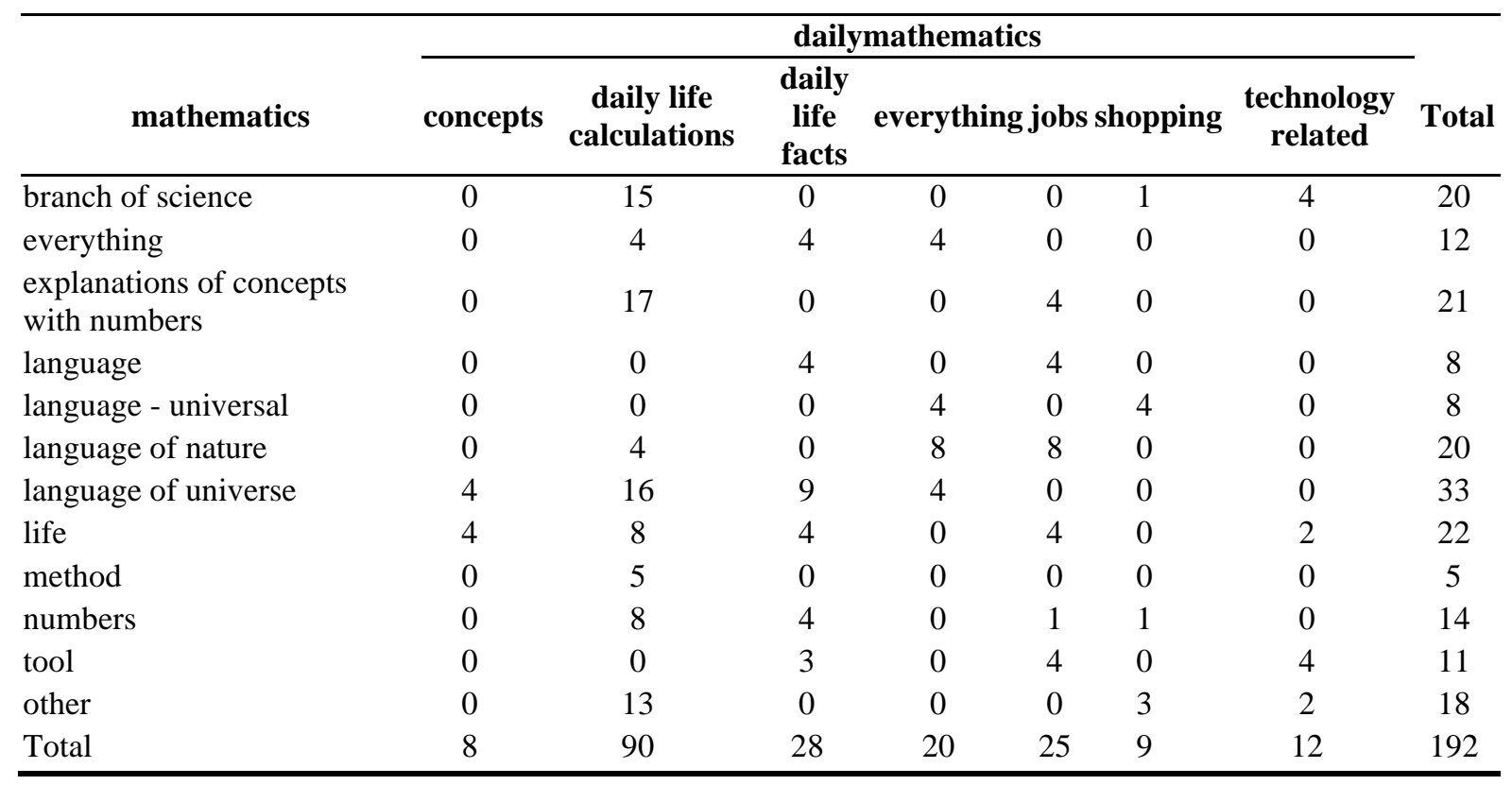

\section{Conclusion, discussion, and implications}

The results of this study showed that mathematics is seen as branch of science, everything, explanations of concepts with numbers, language, universal language, language of nature, language of universe, life, method, numbers, and tool. It is interesting that only males defined mathematics as 'language of nature', 'tool', 'method', and 'language'. Burton (2012) concluded that pre-service teachers perceive mathematics as something that is class related if they have negative attitudes toward it. Here, the themes - branch of science, explanations of concepts with numbers, and numbers - can be associated with class related issues. All of these 
themes emerged with higher rates from the students' data. If we can connect real-life with mathematics in classes, we can help to increase students' attitude toward mathematics.

The themes were compared with respect to occupation of the participants. The top three themes that emerged for students were 'branch of science', 'life', and 'language of universe'. On the other hand, the top three for the teachers were 'language of universe', 'language of nature', and 'explanation of concepts with numbers'.

The results showed that, while $34.7 \%$ of the males state that they learn mathematics because they need it, only $22.2 \%$ of the females state the same. The top second and third themes are different for each gender. For males, the second emerging theme is 'to understand nature', and it was 'to understand life' for females. The third theme for males is 'personal development'; on the other hand, for females, the third theme is 'to understand the universe'. Similarly, Foley (2016) concluded that girls see mathematics as a part of their life, which supports the results of the current study.

Almost half of the participants (49.6\%) gave examples of several daily life calculations for mathematics in their life. Several other researchers also reported similar results (Borthwick, 2011; Epstein, Mendick, \& Moreau, 2010; Young- Loveridge, Taylor, Sharma, \& Hawera, 2006). Also, it was clearly seen that mathematics is viewed as language (language of universe, language of nature, universal language, or simply language) by many of the participants. This result is also consistent with the results of the study by Otte and de Barros (2015).

The results of this study extend what we know about student and teacher perceptions of mathematics and add an important contribution to mathematics education research. As perceptions affect attitudes towards mathematics, future studies can be carried out to find the ways to change perceptions in a way that supports positive attitudes. Future research can be done with elementary school students as this study only focused on high school students and teachers. Moreover, correlational and experimental studies can be conducted to see possible relations with and effects on students' mathematics achievement.

\section{References}

Borthwick, A. (2011). Children's perceptions of, and attitudes towards, their mathematics lessons. In C. Smith (Ed), Proceedings of the British Society for Research into Learning Mathematics 31(1), 37-42.

Burton, M. (2012). What is math? Exploring the perception of elementary pre-service teachers. Issues in the Undergraduate Mathematics Preparation of School Teachers, 5, 1-17.

Cajori, F. (1893). Definition of mathematics. American Mathematical Society (1991 reprint). A History of Mathematics (285-286). New York: AMS Chelsea Publishing.

Epstein, D., Mendick, H., \& Moreau, M.-P. (2010). Imagining the mathematician: young people talking about popular representations of maths. Discourse: studies in the cultural politics of education, 31(1), 45-60.

Foley, C. (2016). Girls' perceptions of mathematics: an interpretive study of girls' mathematical identities. Unpublished EdD Thesis, University of Reading.

Franklin, J. (2009). Aristotelian realism. In A. Irvine (Ed.), The Philosophy of Mathematics (Handbook of the Philosophy of Science series). North-Holland: Elsevier.

Gokalp, M.S. (2018). Multidimensional perceptions of physics. International Journal of Innovation in Science and Mathematics Education, 26(1), 27-45

Mendez-Shannon, E.C. (2010). "We will always be in the shadows" - a qualitative descriptive study of undocumented Latino immigrants surviving in the United States. Unpublished PhD Thesis. University of Iowa, Iowa, USA

Merriam-Webster (2019). Definition of mathematics. Retrieved on April 20, 2019 from https://www.merriamwebster.com/dictionary/mathematics 
Mura, R. (1993). Images of mathematics held by university teachers of mathematical sciences. Educational Studies in Mathematics, 25(4), 375-385.

Otte, M.F., de Barros, L.G.X. (2015). What is mathematics, really? Who wants to know?. Bolema, Rio Claro (SP), 29(52), 756-772.

Parse, R.R. (2001). Qualitative inquiry: The path of sciencing. Boston: Jones \& Bartlett Publishing.

Sandelowski, M. (2000). Focus on research methods whatever happened to qualitative description? Research in Nursing \& Health, 23, 334-340.

Ribeiro, B. (2013). Etymology \& definition of mathematics. Retrieved on April 20, 2019 from https://mathbenny.wordpress.com/2013/02/28/etymology-definition-of-mathematics/

Young-Loveridge, J., Taylor, M., Sharma, S. \& Hawera, N. (2006). Students' perspectives on the nature of mathematics. In P. Grootenboer, R. Zevenbergen \& M. Chinnappan (Eds.), Identities, Cultures and Learning Spaces, 2, 583-590. 